\title{
Elastografinin benign ve malign tiroid nodüllerinin ayırımındaki rolü
}

\author{
The role of elastography in differantiating malignant from benign thyroid nodules
}

\author{
Ergin Sağtaş, Semin Melahat Fenkçi, Şenay Topsakal, Furkan Ufuk, Pınar Çakmak, Osman
} Alparslan

Gönderilme tarihi: 05.03. 2018

Kabul tarihi: 13.07.2018

Özet

Amaç:Kompresif ultrason elastografi incelemesi tiroid nodüllerini değerlendirmeye yarayan non-invaziv ultrason tekniği olup dokunun sertlik ve elastikiyetini inceler ve baskı ile yumuşak dokuların sert dokulara göre daha kolay deforme olabilmesi prensibine dayanır. Dokunun deforme olabilme özelliği malign ve benign lezyonların ayırımında kullanılır. Bu çalışmanın amacı benign ve malign tiroid nodüllerini ayırmada kompresif elastografinin tanı değerini araştırmaktır.

Gereç ve yöntem: Yüzyetmişüç hastada 173 tiroid nodülü ince iğne aspirasyon biyopsisi öncesi gri skala ultrasonografi ve elastografi ile incelenmiştir. Elastografi sonuçları ince iğne aspirasyon biyopsisi sonuçları ile karşılaştırılarak, tiroid nodüllerine uygulanan elastografinin duyarlılık, özgüllük, pozitif ve negatif öngörü değerleri hesaplamıştır.

Bulgular: Histopatoloji sonuçları 162 olguda $(\% 93,6)$ benign, 11 olguda(\%6,4) malign olan nodüller için elastografinin karsinom belirlemedeki duyarlılığı \% 45,4, özgüllüğü \%55,5, pozitif öngörü değeri \%6, negatif öngörü değeri \%94 olarak bulundu. Bu değerlere göre elastografi benign ve malign tiroid nodüllerinin ayırımında istatistiksel olarak anlamlı bulunmamıştır $(p>0,05)$.

Sonuç: Bizim çalışmamızda tiroid nodüllerinin preoperatif tanısında kompresif elastografinin duyarlılık ve özgüllük değerleri önceki çalışmalara göre daha düşük bulunmuştur. Buna göre tiroid nodüllerinin değerlendirilmesinde biyopsi halen en güvenilir tanı yöntemi olarak geçerliliğini korumaktadır.

Anahtar sözcükler: Tiroid nodülü, ultrasonografi, elastografi, ince iğne aspirasyon biyopsisi.

Sağtaş E, Fenkçi SM, Topsakal Ş, Ufuk F, Çakmak P, Alparslan O. Elastografinin benign ve malign tiroid nodüllerinin ayırımındaki rolü. Pam Med J 2019;12:7-12.

\begin{abstract}
Purpose:Strain elastography is a novel noninvasive diagnostic tool that is helpfull in the evaluation of the thyroid nodules. This technique examines the stiffness and hardness of tissue. With the principle that the softer tissue is easily deformed than the harder tissue under external compression, the deformability of tissue was applied to differentiate malignant from benign lesions. The aim of this study was to evaluate the diagnostic value of strain elastography in differentiating malignant from benign thyroid nodules.

Materials and methods:A total of 173 thyroid nodules were examined by gray scale ultrasonography and elastography before fine needle aspiration biopsy in 173 patients. Sensitivity, specificity, positive and negative predictive values of elastography, have been determined by comparing elastography results with fine needle aspiration biopsy results.

Results:For thyroid nodules of which 162 were benign (93.6\%) and 11 malignant (6.4\%) according to histopathology results; the sensitivity, specificity, positive and negative predictive values of elastography in identification of carcinoma were $45.4 \%, 55.5 \%, 6 \%$ and $94 \%$ respectively. According to these values elastography was not statistically significant in differantiating benign and malignant thyroid nodules $(p>0.05)$.

Conclusion:In our study the sensitivity and specificity values of strain elastography in preoperative diagnosis of thyroid nodules were found to be lower in contrast to earlier reports. Our study suggests biopsy is still the most reliable method for the evaluation of thyroid nodules.
\end{abstract}

Key words: Thyroid nodüle, ultrasound, elastography, fine needle aspiration biopsy.

Sağtaş E, Fenkçi SM, Topsakal Ş, Ufuk F, Çakmak P, Alparslan O. The role of elastography in differantiating malignant from benign thyroid nodules. Pam Tıp Derg 2019;12:7-12.

Ergin Sağtaş, Dr.Öğr.Üyesi. Pamukkale Üniversitesi Tıp Fakültesi Radyoloji Anabilim Dalı, DENiZLí, e-posta: esagtas@pau.edu.tr (orcid. org/0000-0001-6723-6593) (Sorumlu yazar)

Semin Melahat Fenkçi, Prof.Dr. Pamukkale Üniversitesi Tıp Fakültesi Radyoloji Anabilim Dalı, DENiZLi, e-posta: sfenkci@yahoo.com (orcid. org/0000-0002-5658-459X)

Şenay Topsakal, Dr.Öğr.Üyesi. Pamukkale Üniversitesi Tıp Fakültesi Radyoloji Anabilim Dalı, DENiZLi, e-posta: topsakals@hotmail.com (orcid. org/0000-0003-4575-5653)

Furkan Ufuk, Dr.Öğretim Görevlisi, Pamukkale Üniversitesi Tıp Fakültesi, Radyoloji Ana Bilim Dalı, DENiZLI, e-posta: furkan.ufuk@hotmail. com (orcid.org/0000-0002-8614-5387)

Pınar Çakmak, Dr.Öğr.Üyesi, Pamukkale Üniversitesi Tıp Fakültesi Radyoloji Anabilim Dalı, DENiZLi, e-posta: pcakmak@pau.edu.tr (orcid. org/0000-0003-4652-6748)

Osman Alparslan, Uzm. Dr. Denizli Özel Sağlık Hastanesi Radyoloji Bölümü, DENiZLil, e-posta: dralparslan@hotmail.com (orcid.org/00000002-1372-6279) 


\section{Giriş}

Nodüler tiroid hastalığı başta iyot eksikliği olan bölgelerde olmak üzere genel popülasyonda sık gözlenmektedir [1]. Tiroid nodülleri olguların ancak $\% 5$ 'inde palpabldır [2, 3]; tiroid ultrasonografisinin kullanıma girmesi ile ise genel popülasyonda \%50'ye varan oranda tespit edilebilmektedir [4, 5]. Ultrasonografide (US) saptanan nodüllerin çoğu asemptomatik ve benign olup nodüllerin ancak \%5'i malign natürdedir $[6,7]$. Nodül tespit edildikten sonraki süreç; tedavi planlaması için nodülün benign ya da malign ayırımının yapılmasıdır [8]. Ultrasonografi eşliğinde ince iğne aspirasyon biyopsisi (IIAB) benign ve malign nodüllerin ayırımında kullanılan en iyi yöntemdir [9].

B-mod US günümüzde tiroid nodüllerinin tespitinde ve tanımlanmasında en iyi görüntüleme yöntemidir. Ancak nodül içi mikrokalsifikasyon, düzensiz kontur, halo işaretinin bulunmayışı ve hipoekojenite gibi özellikler maligniteyi öngörmede yararlı olmakla birlikte düşük duyarlııı ve özgüllüğe sahiptirler $[10,11]$.

Son yıllarda geliştirilen ultrason elastografi tekniği noninvaziv oluşu ve kolay uygulanışı ile birlikte tiroid nodüllerinin değerlendirilmesinde sıkça kullanılmaktadır [12]. Elastografi dokunun sertliğini ve elastikiyetini ölçen noninvaziv bir tanı tekniğidir. Dışardan baskı uygulandığında yumuşak dokular sert dokulara göre daha kolay deforme olmaktadır. Elastografide yumuşak dokuların baskıyla deforme olabilme özelliği benign ve malign tümörlerin ayırımında sıkça kullanılmaktadır [13, 14]. Bu teknik tiroid yanısıra boyun, meme, prostat gibi diğer yüzeyel dokularda da yaygın olarak kullanılmaktadır [ 15 , 16].

Bu çalışmanın amacı, patoloji sonuçları ile kıyaslandığında elastografinin tiroid nodüllerinin benign ve malign ayırımını yapmada doğruluk ve güvenilirliğini araştırmak ve invaziv bir tanı yöntemi olan IIAB gereksinimini azaltıp azaltmadığıdır.

\section{Gereç ve yöntem}

$\mathrm{Bu}$ retrospektif çalışma öncesi lokal etik kuruldan onay alınmıştır. Şubat 2015-Ağustos 2016 tarihleri arasında hastanemize başvuran, fizik muayene ya da US tetkiki ile tiroid nodülü saptanan, tiroid US ile eş zamanlı nodül elastografisi yapılan ve sonrasında US eşliğinde IIAB yapılan olgular çalışmaya dahil edilmiştir.

Inceleme Siemens ACUSON ${ }^{\mathrm{TM}} \mathrm{S} 1000$ US cihazı ile $14 \mathrm{~L} 5 \mathrm{MHz}$ lineer dizilimli prob kullanılarak gerçekleştirilmiştir. Hasta sedyeye supin pozisyonunda yatııımış ve boynunun altına yastık konularak boyun hafif ekstansiyona getirilmiştir. Gri skala US yapıldıktan sonra aynı radyolog tarafından serbest el tekniği ile kompresif elastografi incelemesi yapılmıştır. Bu yöntemde US'de incelenen nodül santralize edilmiş; cilde ve lezyona dik olacak şekilde ultrason probu ile ritmik şekilde hafif kompresyon-dekompresyon manevrası uygulanmıştır. Bu sırada nodülün bir bölgesine ve aynı seviyede komşu normal parankime ROI (region of interest, ilgi alanı) yerleştirilmiştir. Bu şekilde ikiye bölünmüş ekran görüntüsünde sağda gri skala görüntüsü; solda ise gri skala üzerine bindirilmiş translüsan elastografi görüntüsü elde edilmiştir.

Elastografide kırmızı renk en çok elastikiyete sahip yumuşak dokuyu; yeşil renk orta derece elastikiyet-orta sertlikteki dokuyu; mavi renk ise en az elastikiyete sahip olan sert dokuyu temsil etmektedir. Nodülden (A alanı) ve komşu normal parankimden ( $B$ alanı) elde edilen $\mathrm{ROI}$ değerelerinin birbirine oranlanması (B alanı/A alanı) ile cihaz tarafından otomatik olarak elastikiyet indeksi (EI) (strain index) bulunmuş ve veriler kaydedilmiştir (Resim 1). Elastografinin duyarlıı̆̆ını azaltması nedeniyle çevresinde kalsifikasyon bulunan ve büyük bölümü kistik nodüller ile istmus düzeyi ve alt polde lokalize nodüllere elastrografik inceleme yapılmamıştır $[17,18]$.

Tüm olgulara hastanemiz radyoloji kliniğinde, konusunda deneyimli bir radyoloji uzmanı tarafından gri skala incelemede kuşkulu lezyonlara yönelik US eşliğinde IIIAB yapılmıştır. Olguların histopatolojik sonuçları ise benign ve malign olarak sınıflandırıımış ve elastografi sonuçlarıyla karşılaştırılmıştır. Önemi belirsiz atipi ve foliküler neoplazi sitoloji sonuçları olan az sayıdaki hasta çalışmaya dahil edilmemiştir. Tanısal olmayan sitoloji sonucu olan hastaların biyopsileri ise tekrarlanmıştır. Sitoloji sonuçları malign olan olguların tamamının cerrahi patoloji sonuçları malign idi. 


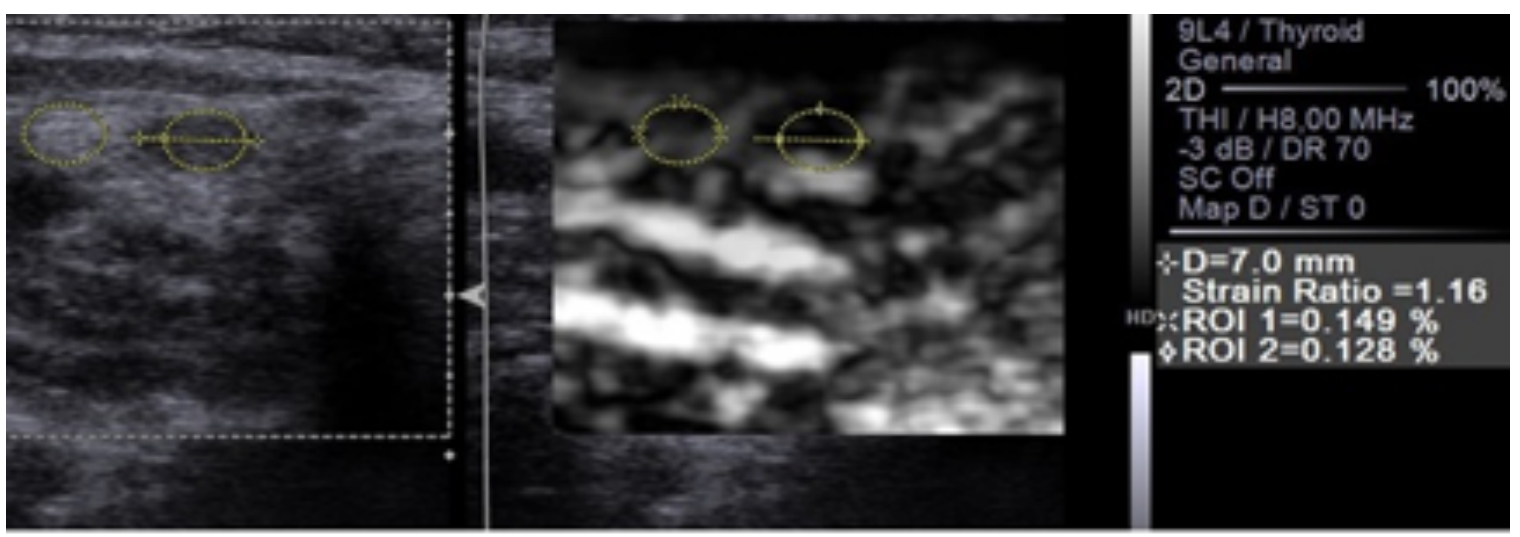

Resim 1. Nodülden ve komşu normal parankimden elde edilen ROI değerlerinin birbirine oranlanması ile otomatik olarak elastikiyet indeksi(El) (strain ratio-index) hesaplanmaktadır. Bu hastada El 1.16 bulunmuştur.

Çalışmada verilerin tanımlayıcı istatistiklerinde ortalama, standart sapma, frekans ve yüzde değerleri kullanılmıştır. Tanı performansının incelenmesinde duyarlılık, özgüllük, pozitif ve negatif öngörü değerleri ve ROC eğirişi yöntemleri kullanılmıştır. Analizlerde SPSS 24.0 (IBM Corp, Chicago, IL) programı kullanılmıştır.

\section{Bulgular}

Olguların yaşları 27 ile 73 arasında olup, ortalama yaş $44 \pm 10.54$ bulundu. Toplam 173 olgunun 118'i (\%68) kadın, 55’i (\%32) erkekti. Nodül çapları $7.5 \mathrm{~mm}$. ile $72 \mathrm{~mm}$. arasında değişmekteydi. Ortalama nodül çapı $22 \pm 12.48$ $\mathrm{mm}$ bulundu.

Histopatoloji sonuçları 162 olguda (\%93.6) benign ve 11 olguda (\%6.4) malign olarak geldi (Tablo 1). Malign olguların tamamının histopatolojisi papiller tiroid karsinomuydu.

Tablo 1. Olguların patoloji ve elastografi sonuçlarına göre dağılımı

\begin{tabular}{lllll}
\hline & \multicolumn{3}{l}{ Patoloji } \\
\hline \multirow{3}{*}{ Elastografi } & Malign & Benign & Total \\
& Malign & 5 & 72 & 77 \\
& Benign & 6 & 90 & 96 \\
& Total & 11 & 162 & 173 \\
\hline
\end{tabular}

Tüm nodüllerin değerlendirilmesinde elastikiyet indeksi (El) değerleri minimum 0,21, maksimum 6,75 bulunmuş olup ortalama değer 1,68 , ortanca değer ise 1,53 bulunmuştur. Benign nodüllerde ortalama El değeri 1,41, ortanca değer 1,37; malign nodüllerde ise ortalama El değeri 3,46, ortanca değer 3,16 bulunmuştur.

El değerleri ile malign tiroid nodüllerinin saptanmasında ROC (Receiver-operating characteristic) eğrisi altında kalan alan 0,5 (\%95 güven aralığı=[0,334-0,673]) idi (Figür 1). Benign ve malign nodüllerin ayırımında en iyi kesim noktası (cutoff point) en yüksek duyarlılık ve özgüllük ile 1,67 bulunmuştur. $P$ değeri 0,968 idi. El verilerine göre duyarlılık \%45,4, özgüllük \%55,5, pozitif öngörü değeri (PPV) \%6 ve negatif öngörü değeri (NPV) \%94 bulunmuştur. $\mathrm{Bu}$ değerlere göre $\mathrm{El} \mathrm{benign} \mathrm{ve} \mathrm{malign} \mathrm{tiroid}$ nodülü ayırımında anlamlı bulunmamıştır $(p>0,05)$.

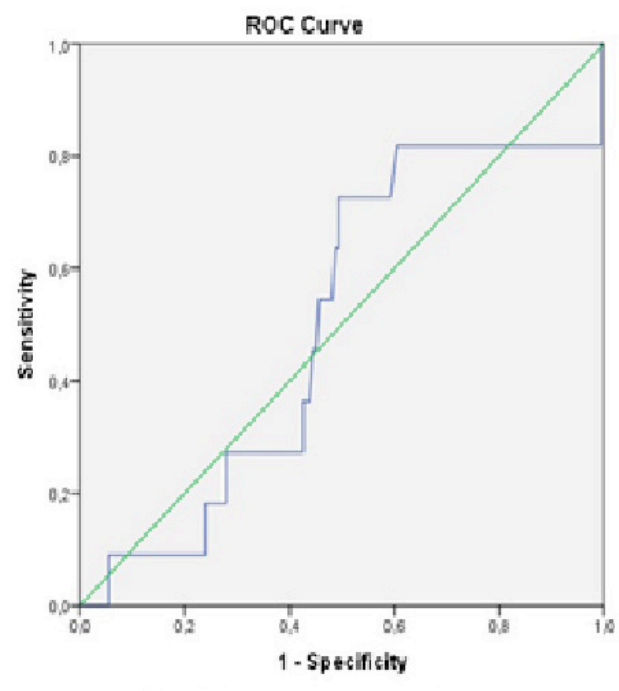

Diagonal segenenils are produced by fins

Grafik 1. Benign ve malign nodüllerin ayırımında ROC eğrisi. Malignite tanısında eğri altında kalan alan 0,5 (\%95 güven aralığı $=[0,334-$ 0,673]) idi. 


\section{Tartışma}

Çalışmamızda tek başına elastografinin tiroid nodüllerinin benign ya da malign ayırımında katkısının olmadığı tespit edilmiştir.

Literatürde tiroid nodüllerinin tanısında elastografi çalışmalarında farklı araştırmacılar tarafından değişik sonuçlar elde edilmiştir [14, 18, 19-25]. Günümüzde iki türlü elastografi tekniği kullanılmaktadır. İlki dışsal baskı kullanılarak yapılan strain (kompresif) elastografi; ikincisi ise cihaz tarafından üretilen ve makaslama dalgasını kullanan shear elastografidir [26]. Rago ve ark. [20] ile Asteria ve ark. [19] tarafından sınıflandırılan ve kalitatif bir yöntem olan elastografi skorlamasının özellikle tamamen kullanıcı bağımlısı olması gibi bazı limitasyonları vardır. Bu limitasyonları aşmak için nodül sertliğini değerlendirmede objektif ve semikantitatif bir yöntem olan strain (elastikiyet) indeksi kullanılmaya başlanmıştır [27]. Bizim çalışmamızda da bu yöntem kullanıımış olup nodül ile komşuluğunda referans olarak alınan normal parankim alanından aynı kesitte ölçüm yapılmakta ve oran cihaz tarafından otomatik olarak hesaplanmaktadır [28].

Literatürde kompresif elastografinin benign ve malign nodül ayırımında yüksek tanısal doğruluğa sahip olduğu birçok çalışmada gösterilmiştir [14, 17, 27, 29, 30]. Buna karşın daha düşük doğruluk oranları bildiren çalışmalar da vardır [31, 32].

Cantisani ve ark. [14] 97 hastayı kapsayan çalışmalarında El kesim noktasını 2 kabul ettiklerinde elastografinin maligniteyi öngörmede gri skala US ve renkli Doppler US'ye göre daha yüksek duyarlılık ve özgüllük değerlerine sahip olduğunu saptamışlardır.

Ning ve ark. [30] 99 solid nodülü kapsayan çalışmalarındabenignvemalignnodülayırımında en iyi kesim noktasını 4,2 bulmuşlardır. Buna göre duyarlılık ve özgüllüğü sırasıyla \%81 ve \%83 saptamışlardır ve elastografinin tanıya katkısı olduğunu bildirmişlerdir.

Ünlütürk ve ark. [31] 194 hasta ve 237 tiroid nodülünü değerlendirdikleri geniş çalışmada elastografinin malign nodül saptamada sınırlı duyarlılık ve pozitif öngörü değerlerine sahip olduğunu ve gri skala US'ye üstünlüğü olmadığını göstermişlerdir. Kagoya ve ark. [32] 44 hastayı inceledikleri çalışmada 1,5 El değerini malignite için kesim noktası kabul ettiklerinde duyarııı̆ı \%90, özgüllüğü \%50 bulmuşlardır ve buna göre elastografinin henüz tanısal performansının yeterli olmadığını ve nodüllerin ayırıcı tanısında gri skala US'ye yardımcı yöntem olarak kullanılabileceğini bildirmişlerdir. Her iki araştırmada önceki çalışmalarda hasta sayılarının az olması, kullanılan parametrelerin ve sınır değerlerinin birbirinden farklılık göstermesi, işlemin kullanıcıya bağlı olması, dışlama kriterlerinin paralellik göstermemesi gibi nedenlerle farklı sonuçların elde edilmiş olabileceğini bildirmişlerdir.

Bizim çalışmamızda da son iki araştırmada $[31,32]$ olduğu gibi elastografinin malign nodülü belirlemedeki duyarlılığı \%45,4, özgüllüğü $\% 55,5$ saptanmış olup literatürdeki diğer çalışmalara göre daha düşük bulunmuştur.

Çalışmamızdaki kısıtılıkların başında çalışmanın küçük popülasyonda yapılmış olması gelmektedir. Çalışmamıza boyut gözetmeksizin tüm nodüller dahil edilmiştir. Ancak üç santimetreden büyük nodüllerde elastografinin güvenilirliği düşüktür. Ayrıca çalışmamızda nodül ayırıcı tanısında kullanılan hipoekojenite, hipoekoik halo, mikrokalsifikasyon gibi gri skala parametreleri değerlendirmeye alınmamıştır. Yanısıra son tanı için benign lezyonlarda sitolojik sonuçlar kullanılmış olup yalancı negatif sitoloji sonuçları dışlanamamıştır. Shear wave elastografi gibi yeni alternatif teknolojik metodlar daha az kullanıcı bağımlı olup daha yüksek kantitatif sonuçlar verebilirdi.

Sonuç olarak bizim çalışmamızda; literatürde genel kabul gören iddianın aksine, elastografinin tiroid nodüllerinde benign ve malign ayırımını yapamadığı gözlenmiştir. Dolayısıyla tanıda geleneksel yöntem olan İIAB'nin hala geçerliliğini koruduğu söylenebilir.

Çıkar İlişkisi: Yazarlar herhangi bir çıkar ilişkileri bulunmadığını beyan eder. 


\section{Kaynaklar}

1. Tunbridge WM, Evered DC, Hall R, et al. The spectrum of thyroid disease in a community: the Whickham survey. Clin Endocrinol (Oxf) 1977;7:481-493.

2. Haugen BR, Alexander EK, Bible KC, et al. 2015 American Thyroid Association Management Guidelines for Adult Patients with Thyroid Nodules and Differentiated Thyroid Cancer: The American Thyroid Association Guidelines Task Force on Thyroid Nodules and Differentiated Thyroid Cancer. Thyroid 2016;26:1133. doi:10.1089/thy.2015.0020

3. Gharib H, Papini E, Garber JR, et al. The AACE/ ACE/AME task force on thyroid nodule. American Association of Clinical Endocrinologists, American College of Endocrinology, and Associazione Medici Endocrinologi Medical, Guidelines for clinical practice for the diagnosis and management of thyroid nodules. Endocr Pract 2016;22:622-639.

4. Russ G, Bonnema SJ, Erdogan MF, et al. European Thyroid Association Guidelines for Ultrasound Malignancy Risk Stratification of Thyroid Nodules in Adults: The EU-TIRADS. Eur Thyroid J 2017;6:225237. doi:10.1159/000478927

5. Aghini-Lombardi F, Antonangeli L, Martino E, et al. The spectrum of thyroid disorders in an iodine-deficient community: the Pescopagano survey. J Clin Endocrinol Metab 1999;84:561-566.

6. Lim DJ, Luo S, Kim MH, et al. Interobserver agreement and intraobserver reproducibility in thyroid ultrasound elastography. Am J Roenthenol 2012;198:896-901.

7. Hegedüs L. Clinical practice. The thyroid nodule. N Engl J Med 2004;351:1764-1771.

8. Hegedüs L, Bonnema SJ, Bennedbaek FN. Management of simple nodular goiter: current status and future perspectives. Endocr Rev 2003;24:102-132.

9. Carmeci C, Jeffrey RB, McDougall IR, et al. Ultrasoundguided fine-needle aspiration biopsy of thyroid masses. Thyroid 1998;8:283-289.

10. Moon WJ, Jung SL, Lee JH, et al. Benign and malignant thyroid nodules: US differentiation-multicenter retrospective study. Radiology 2008;247:762-770.

11. Sipos, J. Advances in ultrasound for the diagnosis and management of thyroid cancer. Thyroid 2009;19:13631372.

12. Hegedüs L. Can elastography stretch our understanding of thyroid histomorphology? J Clin Endocrinol Metab 2010;95:5213-5215.

13. Ophir J, Alam SK, Garra B, et al. Elastography: ultrasonic estimation and imaging of the elastic properties of tissues. Proc Inst Mech Eng H 1999;213:203-233.
14. Cantisani V, D'Andrea V, Biancari F, et al. Prospective evaluation of multiparametric ultrasound and quantitative elastosonography in the differential diagnosis of benign and malignant thyroid nodules: preliminary experience. Eur J Radiol 2012;81:26782683.

15. Lyshchik A, Higashi $T$, Asato R, et al. Cervical lymph node metastases: diagnosis at sonoelastography-initial experience. Radiology 2007;243:258-267.

16. Thomas A, Fischer $\mathrm{T}$, Frey $\mathrm{H}$, et al. Real-time elastography-an advanced method of ultrasound: first results in 108 patients with breast lesions. Ultrasound Obstet Gynecol 2006;28:335-340.

17. Wang Y, Dan HJ, Dan HY, Li T, Hu B. Differential diagnosis of small single solid thyroid nodules using real-time ultrasound elastography. J Int Med Res 2010;38:466-472.

18. Azizi G, Keller J, Lewis M, Puett D, Rivenbark K, Malchoff C. Performance of elastography for the evaluation of thyroid nodules: a prospective study. Thyroid 2013;23:734-740.

19. Asteria C, Giovanardi A, Pizzocaro A, et al. USelastography in the differential diagnosis of benign and malignant thyroid nodules. Thyroid 2008;18:523-531.

20. Rago T, Santini F, Scutari M, Pinchera A, Vitti P. Elastography: new developments in ultrasound for predicting malignancy in thyroid nodules. J Clin Endocrinol Metab 2007;92:2917-2922.

21. Moon HJ, Sung JM, Kim EK, Yoon JH, Youk JH, Kwak JY. Diagnostic performance of gray-scale US and elastography in solid thyroid nodules. Radiology 2012;262:1002-1013.

22. Kwak JY, Kim EK, Kim HJ, Kim MJ, Son EJ, Moon HJ. How to combine ultrasound and cytological information in decision making about thyroid nodules. Eur Radiol 2009;19:1923-1931.

23. Razavi SA, Hadduck TA, Sadigh G, Dwamena BA. Comparative effectiveness of elastographic and B-mode ultrasound criteria for diagnostic discrimination of thyroid nodules: a meta-analysis. AJR Am J Roentgenol 2013;200:1317-1326.

24. Cakir B, Aydin C, Korukluoglu B, et al. Diagnostic value of elastosonographically determined strain index in the differential diagnosis of benign and malignant thyroid nodules. Endocrine 2011;39:89-98.

25. Cantisani V, Grazhdani H, Ricci P, et al. Q-elastosonography of solid thyroid nodules: assessment of diagnostic efficacy and interobserver variability in a large patient cohort. Eur Radiol 2014;24:143-150.

26. Kwak JY, Kim EK. Ultrasound elastography for thyroid nodules: recent advances. Ultrasonography 2014;33:75-82. 
27. Ding J, Cheng HD, Huang J, Zhang Y, Liu J. An improved quantitative measurement for thyroid cancer detection based on elastography. Eur J Radiol 2012;81:800-805.

28. Choi SH, Kim EK, Kwak JY, Kim MJ, Son EJ. Interobserver and intraobserver variations in ultrasound assessment of thyroid nodules. Thyroid 2010;20:167-172.

29. Xing P, Wu L, Zhang C, Li S, Liu C, Wu C. Differentiation of benign from malignant thyroid lesions: calculation of the strain ratio on thyroid sonoelastography. J Ultrasound Med 2011;30:663-669.

30. Ning CP, Jiang SQ, Zhang T, Sun LT, Liu YJ, Tian JW. The value of strain ratio in differential diagnosis of thyroid solid nodules. Eur J Radiol 2012;81:286-291.

31. Unluturk U, Erdogan MF, Demir O, Gullu S, Başkal N. Ultrasound elastography is not superior to grayscale ultrasound in predicting malignancy in thyroid nodules. Thyroid 2012;22:1031-1038.

32. Kagoya R, Monobe H, Tojima H. Utility of elastography for differential diagnosis of benign and malignant thyroid nodules. Otolaryngol Head Neck Surg 2010;143:230234. 